\title{
TINGKAT PENGETAHUAN KADER TENTANG PROGRAM JAMPERSAL PASCA SOSIALISASI DI WILAYAH KERJA PUSKESMAS KEPUTIH KELURAHAN KEPUTIH SURABAYA
}

\author{
Btari Himmatus Shofi.*, Annif Munjidah.** \\ (Universitas Nahdlatul Ulama Surabaya, Jl. Smea 57 Surabaya) \\ Emai: annifmunjidah@yahoo.com
}

Abstract: JAMPERSAL is a government program which is to decrease maternal death and fetal death. Based on first data from the result survey in 5 health volunteer of public hospital at the district Keputih public hospital about JAMPERSAL's knowledge on May 2013 , there was 3 health volunteer who didn't know about JAMPERSAL program. This research is to know the knowledge level of health volunteer about JAMPERSAL after getting a socialization. This research take place at the district of public hospital of Keputih Surabaya.

The research design is using descriptif. The population is every health volunteer of public hospital who joined the socialization of JAMPERSAL at the district Keputih public hospital in 2013 are 20 people. This research are taken by using total sampling with one variable is knowledge level. The research data is primary data taken from quesioner which is fill by the repondent.The data will be processed with editing, scoring, coding, tabulating. Then the data will be analized in descriptif, after that it reserved in frequency distribution table and crossed. Then the next step is to explain the result in naratif.

The result of this research is from 20 respondent, most of them (60\%) have an enough knowledge, (40\%) less knowledge

The conclusion of this research is almost health volunteer who had joined JAMPESAL socialization have an enough knowledge. A public health should be resosialization about JAMPERSAL program for health volunteer by using case study and leaflet

\section{Key word : knowledge, health volunteer, JAMPERSAL}

Jampersal merupakan program pro rakyat yang bertujuan untuk mengurangi AKI dan AKB. Berdasarkan data awal dari hasil survey 5 orang kader posyandu di wilayah kerja Puskesmas Keputih Kelurahan Keputih mengenai pengetahuan program jampersal pada bulan Mei tahun 2013, diperoleh data 3 diantaranya masih belum mengerti sepenuhnya tentang program jampersal. Tujuan penelitian untuk mengetahui tingkat pengetahuan kader terhadap program jampersal pasca sosialisasi di wilayah kerja Puskesmas Keputih Kelurahan Keputih Surabaya.

Desain penelitian adalah deskriptif. Populasi semua kader posyandu yang mengikuti sosialisasi jam persal sebesar 20 kader. Cara pengambilan sampel menggunakan total sampling dengan variable tingkat pengetahuan kader. Pengumpulan data secara primer dari hasil pengisian kuesioner oleh responden. Data yang diperoleh diolah melalui proses editing, scoring, coding, tabulating. Data dianalisis secara deskriptif yang disajikan dalam table distribusi frekuensi dan table silang kemudian menjelaskan hasil pengolahan secara naratif.

Hasil penelitian didapatkan dari 20 responden sebagian besar (60\%) memiliki pengetahuan yang cukup, dan hampir setengahnya (40\%) memiliki pengetahuan kurang. 
Simpulan penelitian adalah kader yang pernah mengikuti sosialisasi jampersal hampir seluruhnya memiliki tingkat pengetahuan cukup. Diharapkan pihak puskesmas untuk melakukan resosialisasi tentang program jampersal ke kader menggunakan studi kasus dan leaflet.

Kata kunci : pengetahuan kader tentang jampersal

\section{PENDAHULUAN}

Masih tingginya angka kematian ibu (AKI) di Indonesia merupakan suatu masalah yang mendapat perhatian besar dari berbagai pihak, baik di dalam maupun di luar negeri. Saat ini kesehatan ibu hamil, dan ibu bersalin di Indonesia masih sangat memprihatinkan dan memerlukan perhatian yang sangat besar (Sarwono, 2009). Berdasarkan data survey Demografi dan Kesehatan Indonesia (SDKI) tahun 2007 menyebutkan bahwa AKI di Indonesia sebesar 228 per 100.000 kelahiran hidup. Angka tersebut masih jauh dari target RPJMN tahun 2014 sebesar 118 per 100.000 kelahiran hidup dan target Millenium Development Goals (MDG's) sebesar 102 per 100.000 kelahiran hidup tahun 2015 (Permenkes RI No. 2562, 2011).

Menurut hasil Riset Kesehatan Dasar (Riskesdas) 2010, persalinan oleh tenaga kesehatan pada kelompok sasaran miskin baru mencapai sekitar 63,3\%, sedangkan persalinan yang dilakukan oleh tenaga kesehatan di fasilitas kesehatan baru mencapai $55,4 \%$. Salah satu kendala penting untuk mengakses persalinan oleh tenaga kesehatan di fasilitas kesehatan adalah keterbatasan dan ketidaktersediaan biaya, sehingga diperlukan kebijakan dan terobosan untuk meningkatkan persalinan yang ditolong tenaga kesehatan di fasilitas kesehatan. Saai ini pemerintah telah menentukan kebijakan yang mendukung hal tersebut yaitu kebijakan yang disebut jaminan persalinan (Jampersal) (Permenkes RI No. 2562, 2011).

Diterapkannya program jampersal ini harus memperoleh tanggapan positif dari tenaga kesehatan di semua lini fasilitas kesehatan. Untuk itu sosialisasi sangat dibutuhkan dalam pengenalan program jampersal ke masyarakat. Langkah riilnya puskesmas sebagai fasilitas kesehatan dasar harus mengadakan sosialisasi kepada para kader posyandunya. Kader posyandu ini selanjutnya menjadi ujung tombak di masyarakat. Aktifnya sosialisasi program jampersal ini diharapkan dapat membantu meratanya informasi jampersal di masyarakat yang selanjutnya diikuti oleh bertambahnya jumlah keikutsertaan. Informasi yang penting dalam sosialisasi ini antara lain tentang biaya, peserta yang boleh mendaftar, alur pendaftaran dan fasilitas yang akan diterima oleh peserta. Keanggotaan ibu hamil dan pemahaman kader tentang jampersal mengerti hakhaknya untuk memperoleh jaminan persalinan sangat penting. Terutama ibu-ibu hamil dari golongan ekonomi lemah atau tidak mampu dapat terliput secara keseluruhan oleh program jampersal sehingga seluruh proses persalinan dapat ditangani oleh tenaga kesehatan yang memiliki kualifikasi persalinan.

Kader posyandu seharusnya membantu para bidan untuk mensukseskan program jampersal dengan ikut serta dalam pendataan warganya yang ingin mengikuti program jampersal. Kader membutuhkan pemahaman tentang program jampersal agar tidak terjadi kesalahan dalam proses aplikasi yaitu mendata warganya yang ingin mendaftar sebagai peserta program jampersal. Upaya sosialisasi sudah dilakukan oleh pihak Puskesmas Keputih pada bulan Februari tahun 2013 kepada kader posyandu yang berada di wilayah Puskesmas Keputih Surabaya. Materi sosialisasi yang telah disampaikan meliputi pengertian, tujuan, sasaran, jenis pelayanan, persyaratan, manfaat, alur. 
Berdasarkan data awal dari hasil survey 5 orang kader posyandu di wilayah kerja Puskesmas Keputih Kelurahan Keputih mengenai pengetahuan program jampersal pada bulan Mei tahun 2013, diperoleh data 3 diantaranya masih belum mengerti sepenuhnya tentang program jampersal. Laporan Jampersal tahun 2012 di Puskesmas Keputih Surabaya diperoleh data 8 dari 36 peserta Jampersal berasal dari non wilayah Puskesmas Keputih Surabaya. Hal itu berarti peserta jampersal dari luar wilayah kerja Puskesmas Keputih hanya sebesar 22,22\%. Hampir seluruhnya $77,78 \%$ berasal dari wilayah kerja Puskesmas Keputih Surabaya.

Pada bulan Januari 2013 ada seorang ibu hamil yang mengalami komplikasi mendapat informasi dari kader posyandu setempat bahwa program jampersal hanya untuk ibu bersalin yang memiliki kartu tanda penduduk (KTP) wilayah Keputih saja, padahal menurut ketentuannya jampersal juga boleh untuk ibu hamil dimanapun sehingga ibu tersebut terlambat dalam memperoleh penanganan yang berakibat pada kematian. Kasus ini menunjukkan bahwa masih kurangnya tingkat pengetahuan kader posyandu tentang program jampersal.

Upaya evaluasi pada program sosialisasi oleh tenaga kesehatan yang berwenang kepada kader posyandu sangat dibutuhkan untuk mengetahui umpan balik terhadap materi yang telah disosialisasikan dengan kejadian yang terjadi setelah sosialisasi. Diharapkan dengan hasil evaluasi tersebut kader posyandu lebih pro aktif dan lebih teliti dalam pendataan peserta jampersal di wilayah Puskesmas Keputih Surabaya.

Berdasarkan masalah yang terjadi di wilayah Puskesmas Keputih Surabaya tentang program jampersal sehingga penulis tertarik untuk melakukan penelitian tentang "Tingkat pengetahuan kader tentang program Jampersal pasca sosialisasi di wilayah kerja Puskesmas Keputih Kelurahan Keputih Surabaya"

\section{METODA}

Desain penelitian yang digunakan oleh peneliti adalah deskriptif yang bertujuan untuk mendeskripsikan secara sistematis, aktual dan akurat terhadap suatu populasi atau daerah tertentu, mengenai Tingkat Pengetahuan Kader Tentang Program Jampersal Pasca Sosialisasi di Wilayah Kerja Puskesmas Keputih Kelurahan Keputih Surabaya. Populasi pada penelitian ini adalah semua kader posyandu yang mengikuti sosialisasi tentang program Jampersal di wilayah kerja Puskesmas Keputih Kelurahan Keputih Surabaya tahun 2013 sebesar 20 kader dan besar sampel sebesar 20 responden dengan Total Sampling.

Pengumpulan data secara langsung menggunakan insrumen lembar kuesioner tentang pengetahuan kader terhadap program jaminan persalinan (Jampersal) pasca sosialisasi di wilayah kerja Puskesmas Keputih Kelurahan Keputih Surabaya. Instrumen tersebut terdiri dari 15 pertanyaan multiplechoice tentang pengertian, manfaat, sasaran, tujuan, alur pendaftaran, tugas kader

Pelaksanaan penelitian ini dilakukan di wilayah kerja Puskesmas Keputih Kelurahan Keputih Surabaya. Adapun pemilihan lokasi tersebut didasarkan atas beberapa pertimbangan antara lain: msyarakat Kelurahan Keputih banyak warga pendatang/tidak tetap, masyarakat Kelurahan Keputih banyak yang ekonominya menengah ke bawah, ketidaktepatan kader dalam pemilihan sasaran program jampersal dan belum pernah dilakukan penelitian sebelumnya mengenai gambaran pengetahuan kader tentang program jampersal. Sedangkan waktu penelitian ini dilaksanakan pada bulan Juni 2013.

Analisis dalam penelitian ini secara deskriptif yang disajikan dalam tabel distribusi frekuensi kemudian langkah 
berikutnya adalah menjelaskan hasil pengolahan secara naratif.

\section{HASIL DAN PEMBAHASAN a. Hasil}

Lokasi penelitian berada di wilayah kerja Puskesmas Keputih Surabaya yang mempunyai batas-batas wilayah sebelah utara Kelurahan Kejawan Putih Tambak Kecamatan Mulyosari, sebelah selatan laut atau Selat Madura, sebelah barat Kelurahan Klampis Ngasem Kecamatan Sukolilo, sebelah timur Kelurahan Wonorejo Kecamatan Rungkut. Luas wilayah kerja Puskesmas Keputih 1448,17 $\mathrm{Km}^{2}$ yang terbagi 1446,3 $\mathrm{Km}^{2}$ untuk Kelurahan Keputih, dan $1,87 \mathrm{Km}^{2}$ untuk Kelurahan Medokan Semampir. Fasilitas kesehatan swasta yang ada di wilayah Kelurahan Keputih antara lain RS Onkologi, RSGM UHT, Medical Centre "ITS", RSB Putri.

Puskesmas Keputih memiliki 33 tenaga kerja termasuk Kepala Puskesmas. Tenaga kerja tersebut meliputi tenaga medis sejumlah 16 orang, tenaga paramedis sejumlah 6 orang, tenaga battra (pengobatan tradisional) 1 orang, staf sejumlah 6 orang, pembantu sejumlah 2 orang, sopir 1 orang, dan keamanan 1 orang.

Kegiatan yang ada di wilayah kerja Puskesmas Keputih Kelurahan Keputih meliputi posyandu balita, dan posyandu lansia. Puskesmas Keputih Kelurahan Keputih memiliki kader dengan jumlah 75 kader posyandu balita dan 5 kader posyandu lansia.

Puskesmas Keputih telah mengadakan sosialisasi tentang program jampersal pada tanggal 2 Maret 2013 dengan jumlah undangan 20 kader di Kelurahan Keputih Surabaya. Materi yang disampaikan pada saat sosialisasi antara lain pengertian, sasaran, persyaratan, rumah sakit atau fasilitas kesehatan rujukan jampersal yang disampaikan oleh bidan Puskesmas Keputih. Pada saat sosisalisasi, pihak Puskesmas Keputih memberikan handout kepada kader sebagai bahan bacaan.

\section{A. Hasil Penelitian}

Karakteristik responden menurut usia, dan pendidikan.

a. Karakteristik Responden Menurut Usia

Pembagian usia berdasarkan pola pikir menurut teori Hurlock (2004). Karakteristik responden menurut usia tergambar dalam tabel 1

Tabel 1 Distribusi Frekuensi Respoinden Menurut Usia Di Wilayah Kerja Puskemas Keputih Kelurahan Keputih Surabaya tahun 2013

\begin{tabular}{ccc}
\hline Usia & Frekuensi & Persentasi \\
\hline $21-40$ & 8 & 40 \\
$41-60$ & 12 & 60 \\
$>60$ & 0 & 0 \\
\hline Jumlah & 20 & 100 \\
\hline
\end{tabular}

Sumber : Data primer Juni 2013

Berdasarkan tabel 1 menunjukkan bahwa dari 20 responden hampir seluruhnya (60\%) berusia berusia 41-60 tahun.

b. Karakteristik Responden Menurut

Distribusi frekuensi responden menurut pendidikan kader ditunjukkan pada tabel 2

Tabel 2 Distribusi Frekuensi Responden Menurut Pendidikan Di Wilayah Kerja Puskemas Keputih Kelurahan Keputih Surabaya tahun 2013

\begin{tabular}{ccc}
\hline Pendidikan & Frekuensi & Persentasi \\
\hline Dasar & 5 & 25 \\
Menengah & 12 & 60 \\
Tinggi & 3 & 15 \\
\hline Total & 20 & 100 \\
\hline
\end{tabular}

Sumber : Data primer Juni 2013

Berdasarkan tabel 2 menunjukkan bahwa dari 20 responden hampir seluruh nya $(60 \%)$ responden berpendidikan menengah. 
1. Data Khusus

a. Karakteristik Responden Menurut Tingkat Pengetahuan

Distribusi frekuensi responden menurut tingkat pengetahuan tergambar dalam tabel 3 Tabel 3 Distribusi Frekuensi Responden Menurut Tingkat Pengetahuan Di Wilayah Kerja Puskesmas Keputih Kelurahan Keputih Surabaya tahun 2013

\begin{tabular}{ccc}
\hline $\begin{array}{c}\text { Tingkat } \\
\text { Pengetahuan }\end{array}$ & Frekuensi & Persentasi \\
\hline Baik & 0 & 0 \\
Cukup & 12 & 60 \\
Kurang & 8 & 40 \\
\hline Total & 20 & 100 \\
\hline
\end{tabular}

Sumber : Data primer Juni 2013

Berdasarkan tabel 3 menunjukkan bahwa dari 20 responden hampir seluruhnya $(60 \%)$ responden memiliki tingkat pengetahuan cukup.

b. Karakteristik Responden Menurut Tingkat Pengetahuan Tahu

Berikut merupakan tabel dari distribusi frekuensi responden menurut tingat pengetahuan tahu.

Tabel 5.4 Distribusi Frekuensi Responden

Menurut Tingkat Pengetahuan

Tahu Di Wilayah Kerja Puskemas

Keputih Kelurahan Keputih Surabaya tahun 2013

\begin{tabular}{ccc}
\hline $\begin{array}{c}\text { Tingkat } \\
\text { Pengetahuan }\end{array}$ & Frekuensi & Persentasi \\
\hline Baik & 3 & 15 \\
Cukup & 9 & 45 \\
Kurang & 8 & 40 \\
\hline Total & 20 & 100 \\
\hline
\end{tabular}

Sumber : Data primer Juni 2013

Berdasarkan tabel 4 menujukkan bahwa sebagian dari responden (45\%) memiliki tingkat pengetahuan tahu yang cukup.

c. Karakteristik Responden Menurut Tingkat Pengetahuan Memahami

Karakteristik Responden Menurut Tingkat Pengetahuan Memahami Di Wilayah
Kerja Puskemas Keputih Kelurahan Keputih Surabaya tahun 2013

Tabel 5 Distribusi Frekuensi Responden Menurut Tingkat Pengetahuan Memahami Di Wilayah Kerja Puskemas Keputih Kelurahan Keputih Surabaya tahun 2013

\begin{tabular}{ccc}
\hline $\begin{array}{c}\text { Tingkat } \\
\text { Pengetahuan }\end{array}$ & Frekuensi & Persentasi \\
\hline Baik & 2 & 10 \\
Cukup & 9 & 45 \\
Kurang & 9 & 45 \\
\hline Total & 20 & 100 \\
\hline
\end{tabular}

Sumber : Data primer Juni 2013

Berdasarkan tabel 5 menunjukkan bahwa sebagian dari responden (45\%) memiliki tingkat pengatahuan memahami yang cukup dan kurang.

d. Karakteristik Responden Menurut Tingkat Pengetahuan Aplikasi

Karakteristik Responden Menurut Tingkat Pengetahuan Aplikasi Di Wilayah Kerja Puskemas Keputih Kelurahan Keputih Surabaya tahun 2013

Tabel 6 Distribusi Frekuensi Responden Menurut Tingkat Pengetahuan Aplikasi Di Wilayah Kerja Puskemas Keputih Kelurahan Keputih Surabaya tahun 2013 Tingkat Frekuensi Persentasi Pengetahuan

\begin{tabular}{crc}
\hline Baik & 7 & 35 \\
Cukup & 11 & 55 \\
Kurang & 2 & 10 \\
\hline Total & 20 & 100 \\
\hline
\end{tabular}

Sumber : Data primer Juni 2013

Berdasarkan tabel 6 menunjukkan bahwa hampir seluruhnya (55\%) responden memiliki tingkat pengatahuan aplikasi yang cukup. 


\section{b. Pembahasan}

Pengetahuan dalam penelitian ini dibagi dalam 3 tingkat yaitu tahu, memahami, dan aplikasi. Berdasarkan tabel 4 menunjukkan bahwa hampir setengahnya $(45 \%)$ responden memiliki tingkat pengetahuan tahu yang cukup. Tahu merupakan tingkat pengetahuan yang paling dasar, untuk sekedar tahu seharusnya kader memiliki pengetahuan yang baik karena program ini sudah banyak dikenal masyarakat. Tingkat pengetahuan tahu penting untuk bekal dalam menjelaskan program jampersal ke masyarakat dengan benar sesuai dengan prosedur. Hal ini sesuai dengan teori menurut Notoatmodjo (2010) bahwa tahu diartikan sebagai mengingat suatu materi yang telah dipelajari sebelumnya, tahu merupakan tingkat pengetahuan paling rendah. Tingkat tahu adalah mengingat kembali (recall) terhadap sesuatu yang spesifik dari seluruh bahan yang dipelajari atau rangsangan yang telah diterima.

Berdasarkan analisis soal tentang jenisjenis pelayanan dalam jampersal dan soal tentang alur pengurusan jampersal hampir seluruhmya $(65 \%)$ dari 20 kader memiliki tingkat pengetahuan memahami yang kurang. Pemahaman kader yang kurang dapat menimbulkan kesalahpengertian di tataran masyarakat. Hal itu disebabkan dalam program jampersal kader merupakan "kepanjangan tangan" (penerus fungsi) puskesmas atau bidan dalam proses memberikan penjelasan secara benar tentang program jampersal. Hal ini sesuai dengan teori menurut Yulifah; Yuswanto, 2009 salah satu peran kader adalah melakukan komunikasi, memberikan informasi, dan motivasi tatap muka (kunjungan) dengan menggunakan alat peraga, serta melakukan demonstrasi (memberikan contoh).

Berdasarkan analisis soal tentang kasus pasien operasi sectio caesaria setengahnya (50\%) dari 20 kader memiliki tingkat pengetahuan aplikasi yang cukup. Pada tingkat pengetahuan aplikasi seharusnya kader memiliki tingkat pengetahuan yang baik karena kader memiliki tugas untuk melakukan pendataan dan pemilihan sasaran yang tepat. Bekal pengetahuan kader cukup, maka akan berpengaruh terhadap ketidaktepatan dalam memilih sasaran sehingga akan terjadi keterlambatan dalam pelayanan ibu.. Hal ini sesuai dengan teori Notoatmodjo (2010) aplikasi diartikan sebagai kemampuan untuk menggunakan materi yang telah dipelajari pada situasi atau kondisi sebenamya. Aplikasi disini dapat diartikan sebagai penggunaan hukumhukum, rumus, metode, prinsip, dan sebagainya dalam situasi dan konteks yang lain. Misalnya dapat menggunakan prinsipprinsip siklus pemecahan masalah di dalam pemecahan masalah kesehatan dari kasus yang diberikan.

Usia merupakan salah satu faktor yang mempengaruhi tingkat pengetahuan. Sebagian besar $(60 \%)$ responden di wilayah kerja Puskesmas Keputih Kelurahan Keputih Surabaya berusia 41-60 tahun. Pada fase dewasa madya seseorang akan lebih memiliki pemikiran matang terhadap segala sesuatu yang dialaminya. Kader yang ada pada fase dewasa madya dapat memahami sesuatu hal yang diterima. Kematangan usia dapat mempengaruhi upaya sosialisasi serta pemanfaatan program jaminan persalinan (jampersal) ke masyarakat. Hal ini sesuai dengan teori menurut Notoatmodjo (2010), tingkat pengetahuan ibu akan berkembang seiring bertambahnya usia. Semakin cukup usia, tingkat kematangan dan kekuatan seseorang akan lebih matang dalam berfikir dan mengambil keputusan. Semakin matang usia, maka semakin banyak informasi yang dijumpai, semakin banyak pula yang dikerjakan. Sedangkan pada usia lebih tua kepedulian untuk mendapatkan informasi berkurang. Selain daya ingat, konsentrasi dan keinginan seseorang untuk memperoleh pengetahuan juga menurun. Menurut WHO, memori atau daya ingat seseorang itu salah satunya dipengaruhi oleh umur.

Berdasarkan tabel 2 didapatkan dari 20 responden hampir seluruhnya (60\%) berpendidikan menengah (SMA). Kader yang mempunyai tingkat pendidikan memadai (SMA) dapat memahami suatu 
informasi dengan lebih mudah. Bekal pengetahuan yang memadai tersebut dapat membantu meningkatkan kinerja kader dalam pendataan peserta jampersal. Hal ini didukung teori menurut Notoatmodjo (2010) makin tinggi pendidikan seseorang makin mudah menerima informasi sehingga makin banyak pula pengetahuan yang dimiliki. Sebaliknya pendidikan yang kurang akan menghambat perkembangan sikap seseorang terhadap nilai-nilai yang baru dikenal.

\section{SIMPULAN}

Kader di wilayah kerja Puskesmas Keputih Kelurahan Keputih Surabaya hampir seluruhnya memiliki pengetahuan yang cukup tentang program jampersal pasca sosialisasi.

1. Bagi Puskesmas

Diharapkan untuk melakukan resosialisasi khususnya tentang syarat, dan sasaran program jampersal dengan metode penyampaian materi yang berbeda seperti memberikan contoh kasus yang bervariasi, serta pemberian materi tertulis dengan selebaran brosur yang berisi tentang materi program jampersal.

2. Bagi Responden

Berdasarkan hasil penelitian ini diharapkan kader dapat membaca kembali materi yang telah diberikan pihak puskesmas handout untuk meningkatkan pengetahuan tentang program jampersal sehingga tepat dalam penjelasan dan pendataan peserta jampersal.

\section{Bagi STIKES YARSIS}

Diharapkan hasil penelitian ini sebagai kontribusi ilmiah berupa tambahan informasi, fakta dan data bagi perpustakaan tentang program jampersal, serta dapat digunakan sebagai referensi yang dapat digunakan bahan penelitian selanjutnya

\section{DAFTAR RUJUKAN}

Arikunto, S. 2006. Prosedur Penelitian Suatu Pendekatan Praktek. Jakarta, Bhineka Cipta.

Drajat, Agus. 2010. Buku Saku Jampersal. http://agus34drajat.files.wordpress.co $\mathrm{m} / 2010 / 10 / \mathrm{buku}$-saku-jampersall.pdf.

Erfandi. 2009. Pengetahuan. Akses http://forbetterhealth.wordpress.com. Artikel ini diakses tanggal 4 April 2013

http://www.depkes.go.id/downloads/PERAT URAN_MENTERI_KESEHATAN_JU KNIS_JAMPERSAL.pdf. Artikel ini diakses tanggal 4 April 2013

Istigfaiyah, Lily. 2013. Tujuan Sosialisasi. http://lilyistigfaiyah.blogspot.com/201 3/01/tujuan-sosialisasi.html. Artikel ini diakses tanggal 8 Mei 2013

Khadafi, Rizal. 2010. Undang Undang Dasar 1945. Jakarta : Bukuné

Mashudi, Sugeng. 2012. Buku Ajar Sosiologi Keperawatan Konsep dan Aplikasi. Jakarta : EGC

Melani. 2012. Cara Pengukuran Keberhasilan Sosialisasi. http://www.wordpress.com. Artikel ini diakses tanggal 8 Mei 2013

Mubarak, Iqbal Wahit. 2009. Sosiologi Untuk Keperawatan Pengantar dan Teori. Jakarta : Salemba Medika

Notoatmodjo, Soekidjo. 2010. Metodologi Penelitian Kesehatan. Jakarta : PT. Rineka Cipta

Notoatmodjo, Soekidjo. 2010. Pendidikan dan Perilaku Kesehatan. Jakarta : PT. Rineka Cipta

Nursalam. 2008. Konsep dan Penerapan Metodologi Penelitian Ilmu Keperawatan. Jakarta : Salemba Medika

Prawirohardjo, Sarwono. 2009. Ilmu Kebidanan. Jakarta : Yayasan Bina Pustaka Sarwono Prawirohardjo

Rahmayanti, Pipit. 2013. Pembinaan Kader. http://pipitrahmayanti.blogspot.com. Artikel ini diakses tanggal 4 April 2013 
Septian, Sela. 2012. Sosialisasi dan Tujuan Sosialisasi.

http://selaseptian020.blogspot.com/20 12/09/sosialisasi-tujuan-sosialisasi dan.html\#ixzz2TSLVGTdA. Artikel ini diakses tanggal 8 Mei 2013

Setiadi, E. M. , Kolip, Usman. 2010. Pengantar Sosiologi. Jakarta : Refika Aditama

Wahyu, Ramdani. 2007. ISD (ILMU SOSIAL DASAR). Bandung : Pustaka Setia 
